\title{
Correction to: The macro-economic determinants of health and health inequalities - umbrella review protocol
}

\author{
Yannish Naik ${ }^{1,2^{*}+} \mathbb{D}$, Peter Baker ${ }^{3+}$, lan Walker ${ }^{4}$, Taavi Tillmann ${ }^{5}$, Kristin Bash$^{1}$, Darryl Quantz ${ }^{6}$, \\ Frances Hillier-Brown ${ }^{7}$ and Clare Bambra ${ }^{8}$
}

\section{Correction to: Syst $\operatorname{Rev}(2017)$ 6:222 https://doi.org/10.1186/s13643-017-0616-2}

Following publication of the original article [1], the authors opted to correct the following reference on page 3 :

The economy has been defined as a 'social domain that emphasizes the practices, discourses, and material expressions associated with the production, use and management of resources' [8].

It should have been:

The economy has been defined as a 'social domain that emphasizes the practices, discourses, and material expressions associated with the production, use and management of resources' [52].

52. James P, Magee L, Scerri A, Steger MB (2015). Urban Sustainability in Theory and Practice: Circles of Sustainability. London: Routledge. p. 53.

The authors apologize for the inconvenience caused.

\section{Author details}

'Leeds Teaching Hospitals NHS Trust, Leeds, UK. ${ }^{2}$ Leeds Institute of Health Sciences (LIHS), Level 10, Worsley Building, Clarendon Way, Leeds LS2 9NL, UK. ${ }^{3}$ Imperial College London, London, UK. ${ }^{4}$ Nuffield Centre for International Health and Development, University of Leeds, Leeds, UK. ${ }^{5}$ University College London, London, UK. ${ }^{6}$ University of Lancaster, Lancaster, UK. ${ }^{7}$ Institute for Health \& Society, University of Newcastle, Newcastle upon Tyne, UK.

${ }^{8}$ Newcastle University, Newcastle upon Tyne, UK.
Published online: 07 September 2019

\section{Reference}

1. Naik Y, Baker P, Walker I, Tillmann T, Bash K, Quantz D, Hillier-Brown F, Bambra C. The macro-economic determinants of health and health inequalities - umbrella review protocol. Syst Rev. 2017;6:222 https://doi.org/ 10.1186/s13643-017-0616-2.

* Correspondence: yannishnaik@nhs.net

†Yannish Naik and Peter Baker contributed equally to this work

${ }^{1}$ Leeds Teaching Hospitals NHS Trust, Leeds, UK

${ }^{2}$ Leeds Institute of Health Sciences (LIHS), Level 10, Worsley Building,

Clarendon Way, Leeds LS2 9NL, UK 